\title{
Case Study Of Manor New Tech High School: Promising Practices In STEM Education For Comprehensive High Schools
}

Hannah Gourgey, E3 Alliance, USA

Bahram Asiabanpour, Texas State University- San Marcos, USA

Carol Fenimore, E3 Alliance, USA

\begin{abstract}
The following paper culminates a year of research conducted by researchers at $E^{3}$ Alliance and Texas State University and sponsored by the National Science Foundation. The following reports on promising practices observed and reported at Manor New Tech High School (MNTH), a Texas Science Technology Engineering Mathematics (T-STEM) high school in Manor Independent School District (ISD) that opened in August 2007. MNTH follows several high school redesign principles such as small learning communities and rigorous coursework with real-world applications, and is focused on Science, Technology, Engineering, and Mathematics (STEM). Through a case study analysis based on teacher surveys, interviews, and site visits, the researchers identify practices that potentially apply to comprehensive high schools committed to improving student outcomes in STEM fields.
\end{abstract}

Keywords: Secondary Education; STEM Education; Project-Based Learning; Student Agency; Small Schools; Teacher Professional Development; Teacher Advancement Program

\section{INTRODUCTION}

e designed this case study to identify teacher and school practices that directly support STEM
education and that could be adapted and be helpful to a comprehensive high school setting. We
chose MNTH because of its reputation as a school that had the resources and leadership to follow the New Technology High School model ${ }^{1}$ with fidelity; its student population, which is majority students of color (67 percent) and economically disadvantaged (56 percent); and its proximity to the school districts participating in the National Science Foundation grant for the expansion and improvement of engineering education in Central Texas.

Manor New Tech High School opened in August 2007 as an independent campus at the former Manor Middle School. Its layout design reflects the tenets of small schools design and provides the 1:1 student-tonetworked computer ratio expected in the New Technology High Schools model. By 2008-09, when the study commenced, MNTH served 212 students from grades nine through eleven and grew to a complete four year high school in 2009-10. There are no admission criteria per se, but each student gains entry by completing an application. The administration then conducts a lottery so that the same number of male and female students matriculates. MNTH ethnic and income demographics are similar but do not exactly parallel the demographics of Manor High School, the district's comprehensive high school. In 2007-2008, Manor High School had a slightly higher proportion of low income students (59.7\% compared to $54.1 \%$ at MNTH), a greater portion of English language learners $(11.5 \%$ versus $5.1 \%$ at $\mathrm{MNTH})$, a smaller portion of white students $(17.1 \%$ versus $28.7 \%$ at

\footnotetext{
${ }^{1}$ Founded in1996 in Napa Valley, California; see http://www.newtechhigh.org/about-NTHS.html.
} 
$\mathrm{MNTH}$ ), and a greater portion of African American students (32.2\% versus $23.6 \%$ at MNTH). ${ }^{2}$

In addition to the New Technology High School model, MNTH incorporates several other programs and initiatives in support of student learning of STEM content. These include Project Lead the Way (PLTW), FIRST Robotics, and Apple Classrooms of Tomorrow-Today $\left(\mathrm{ACOT}^{2}\right)^{3}$. Also, MNTH faculty participates in the Teacher Advancement Program system for annual assessment and on-going professional development.

Of the 22 faculty, 9 teachers are experienced teachers with 5 or more years in teaching. All are certified in their subject areas, and all are teaching in their fields of certification. Half of Manor New Tech High teachers held some previous career before entering teaching. Also, six teachers come from a specialized teaching program developed at The University of Texas at Austin called UTeach. UTeach produces certified teachers in mathematics and science who had majored in a natural sciences field in their bachelor's program and took substantial coursework in courses in their educator program on project-based learning and problem-based inquiry instruction in STEM fields. Also notable is that from the 2008-2009 to the 2009-2010 school year there was no faculty turnover versus a regional one-year turnover rate of 18 percent. $^{4}$

Our research questions are:

1. What practices from MNTH that facilitate student learning of STEM that could be implemented at traditional high schools?

2. What are the possible benefits to each of the practices? For each practice, what are the possible limits or constraints when implemented in a high school that is new to STEM?

3. In particular, in what ways does the Project Leadership The Way program provide students entrée into college level coursework?

\section{METHODOLOGY}

Given the small scope of the study and that Manor New Tech High School had only just completed its second full school year; we opted to use a blended methodology that includes both quantitative and qualitative approaches. Specifically, we conducted teacher surveys (for a review of the survey see Appendix A), interviews with a selection of teachers representing the range of experience at MNTH, site visits, and student performance data. The research began with observations of faculty meetings and Monday-morning faculty development meetings to learn more about their process in utilizing Teacher Advancement Program (TAP) professional development and mentoring. A survey of all 22 faculty followed and was staged at the beginning of the third trimester; 19 responded for a 86 percent return rate. Staging the survey at the beginning of the third trimester helped ensure that new faculty at MNTH had enough time to experience MNTH and provide more informed reflection in their survey responses.

Following the administration of the survey and initial data analysis, we selected six teachers for in-depth interviews that enabling these teachers to elaborate on themes that emerged in the survey responses. The teachers we selected represented a range of the following characteristics: (1) Experience with the New Tech model, (2) Experience with Project Lead the Way, (3) UTeach alumni ${ }^{5}$, (4) First year at Manor New Tech High, (5) Held a previous career, (6) New Teacher or Master Teacher. We conducted interviews in the last few weeks of the school year to help ensure teachers could look back on their experience in 2008-2009.

\footnotetext{
2 Texas Education Agency developed the "comparison group" model as a way for districts to compare their performance to districts with similar demographic characteristics. The group is comprised of 40 schools that share similar demographics on 6 characteristics: \% African American students enrolled, \% Hispanic students enrolled, \% White students enrolled, \% economically disadvantaged students enrolled, $\%$ of mobile students as determined from previous years cumulative attendance and \% English Language Learners enrolled. While schools are grouped in this manner, districts are not. Data retrieved on April 21, 2009 from http://ritter.tea.state.tx.us/perfreport/ci/2008/index.html.

${ }^{3}$ Apple Classrooms of Tomorrow-Today (ACOT2) White Paper, retrieved from http://images.apple.com/education/highschool/media/ACOT2 Overview.pdf on August 20, 2009.

${ }_{5}^{4}$ E3 Alliance analysis of data from Dr. Ed Fuller, College of Education, The University of Texas at Austin.

${ }^{5}$ The UTeach program was launched at The University of Texas at Austin as a collaboration between the Colleges of Education and Natural Sciences. Students are provided intensive training in Project-base Learning and Problem-based Inquiry as the primary instructional approaches to teaching in STEM fields.
} 
The focus of this research effort was to identify what teachers believe are effective practices with students and fellow teachers, in particular, their use of specific instructional strategies, peer interactions (both structured and unstructured), peer attitudes, teacher support, school leadership, and general school and district factors. Also, we explored practices that create challenges that teachers believe impede their effectiveness in delivering STEM content and skills to their students and, thereby, affect student academic performance.

The focus on teacher perception of best practices was both deliberate - a belief that practitioners offer a unique and critically important purview into the practical application of certain approaches - and, pragmatic - due to the newness of Manor New Tech High, longitudinal data on student performance was not yet available.

Without longitudinal student performance data and also lacking access to matched student data, our findings on promising teacher and school practices are not correlated or causative in relation to student achievement or improvements to student achievement. We do, however, identify promising practices, each with a recommendation or suggestion for further research.

\section{ASSUMPTIONS \& LIMITATIONS}

1. The Manor New Tech Model is achieving positive student outcomes at a greater rate than traditional comprehensive high schools. We have only limited access to student data proving this point.

2. Schools that have been around for many years face challenges to new program implementation not at issue for newly-launched schools - this reality will be a consideration when identifying those promising practices most likely to translate to a comprehensive high school.

3. While funding of programmatic changes may be a consideration in identifying those promising practices most likely to translate to a comprehensive high school, we did NOT eliminate recommendations that require additional financial support or reallocation of resources. The limited scope of this study did not allow for us to conduct surveys or interview the following key populations or stakeholders: MNTH students, MNTH administrators, comprehensive high school teachers and administrators, or parents of MNTH students

As a result of this scope, recommendations of promising practices will be paired with recommendations for further research that would allow us to test the validity of these findings.

\section{LITERATURE REVIEW}

Educational researchers Carnavale and Desrochers (2003) argue that the American education system is antiquated, obsolete and inadequate in preparing our youth for the education and career demands of the $21^{\text {st }}$ century. 6 Their report, issued in the heat of debate around high school redesign, applauded efforts to improve rigor in the core subjects of English language arts, mathematics, science and social studies but argued that U.S. public school curricula needed integration of content and applied approaches, alignment to higher education coursework, and development of student "professional" or "soft" skills sought by U.S. industries. ${ }^{7}$ Indeed over the last two decades experiments in school structures, instructional strategies and content had been fully underway. The following literature review includes only the specific models or approaches that MNTH employs.

\section{New Tech Model}

In 1999, supporters of the Napa New Tech High School, which was founded in 1996 expressly to address $21^{\text {st }}$ century skills for $11^{\text {th }}$ and $12^{\text {th }}$ graders, launched the New Technology Foundation to explore and promote a model of school reform centered on project-based learning instructional strategies, integrated curriculum across core subjects, technology integration, and a selection of tools and materials designed to enhance instruction and student engagement. ${ }^{8}$

\footnotetext{
${ }^{6}$ Carnavale, A. and Desrochers D. (2003). "Standards for What? The Economic Roots for Education Reform" Education Testing Service Princeton, NJ.

${ }^{7}$ Ibid, p 53

${ }^{8}$ New Technology Foundation website: Retrieved July 13, 2009 from http://www.newtechfoundation.org/about.html
} 
Since 1999, "New Tech" high schools have sprung up across the nation centered on seven critical principles. Schools were not to exceed 400 students for grades 9-12, and the ratio of students to networked computers was no less than 1:1. Curricula are grounded in collaborative learning environments and the projectbased learning model. Professional development for teachers and staff is on-going and diverse in content but focused on project-based learning instructional strategies. The principal has autonomy in hiring fully-dedicated faculty, a New Tech Foundation advocate on site, and an Information Technology Administrator to support school systems. The school is physically separated from other school models to create a unique identity and provide classrooms with diverse learning environments. Finally, industry-school partnerships are on-going and provide critical career awareness and professional skills to high school students. ${ }^{9}$

Despite tremendous growth in the New Tech high school movement that now includes model high schools in over 9 states across the country with concentrations in California, Indiana and North Carolina, there have been few objective, longitudinal evaluations of student outcomes. Much of this research has instead focused on case studies of the New Tech Model or on broader trends such as the small-schools initiative. Still, current literature show overall positive student outcomes in these case studies.

Studies of the New Tech model conducted via survey and classroom observation emphasized the positive effect on teaching. For example, in the fall of 2007, the Buck Institute for Education (BIE) conducted a national survey of high school reform and project based learning (PBL). The study included teachers from several major high school reform networks that emphasize PBL as an instructional approach: New Tech High, High Tech High, Edvision Schools, and Envision Schools. It also included a variety of other small high school reform sites and comprehensive high schools that were not formally associated with a specific reform model. ${ }^{10}$

Compared to other teachers in the study, teachers in New Tech schools more frequently:

- $\quad$ Had extensive professional development in using PBL

- $\quad$ Gave reasons for using PBL that included teaching skills beyond academics

- $\quad$ Conducted projects that specified content standards, used rubrics, and created a need to know prior to teaching the content

- $\quad$ Conducted PBL with fewer commonly-stated obstacles such as lack of time or subject-specific models

- $\quad$ Said teachers were involved in school decision-making and leadership

- $\quad$ Identified school-wide structures that supported PBL and integrated curriculum strategies

- $\quad$ Reported higher levels of student engagement

In general, teachers working in New Tech schools were satisfied even as they acknowledged that much of the work required a lot of planning and preparation prior to the start of any new class project. ${ }^{11}$

\section{Small Schools}

On the other hand, evaluations of smaller learning communities demonstrate mixed results in comparison to the more positive representation of teaching illustrated in the BIE study. For example, a recently released study by the New School for Management on New York City's Small School reforms for their high schools indicted mixed results in the academic performance of small schools. While student attendance improved and graduation rates rose, these small schools struggled with teacher turnover and student attrition into the nearest comprehensive high school. Furthermore, comprehensive high schools experienced setbacks with the draw of teachers and administrators to the smaller schools effort, including greater overcrowding, higher dropout rates, higher rates of "hard-to-reach" student populations, such as English Language Learners and those in special education. ${ }^{12}$

\footnotetext{
${ }^{9}$ New Technology Foundation website: Retreved on June 30, 2009 from http://www.newtechfoundation.org/initaitves process.html

${ }^{10}$ Ravitz, J. (2008). New Tech High Schools: Results of the National Survey of Project Based Learning and High School Reform conducted by the Buck Institute for Education. Novato, CA: Buck Institute for Education

${ }^{11}$ Ibid.

${ }^{12}$ Hemphill, Clara and Kim Nauer, et al. (2009) "The New Marketplace: How Small-School Reforms and School Choice Have Reshaped New York City’s High Schools." Center for New Your City Affairs: Milano The New School for Management and Urban Policy.
} 
This study concludes with ten recommendations, three of which help support the pursuit of this current study.

- $\quad$ Look beyond small school model as the only option for struggling students

- $\quad$ Find ways to support mid-size mixed ability schools that can offer a wider range of services and courses than a small school setting, but will not swallow up kids as large comprehensive schools risk doing

- Identify systemic strategies to support English Language Learner populations and students in special education programs ${ }^{13}$

\section{Project Lead the Way}

Another strategy that has been employed in high school redesign focuses on modifying core curriculum for more integration among the core subject areas and providing "real-world" applications of key concepts, particularly in STEM related subjects. Project Lead the Way (PLTW) is a program in engineering designed by the Rochester Institute of Technology and local school districts that strives toward such integration and application. The Southern Regional Education Board (SREB) High Schools That Work Division conducted a study to determine whether the PLTW engineering pathway provided participating students with higher quality learning experiences - leading to higher achievement - when compared to other non-participating students in the High Schools that Work network. These studies found that PLTW students showed significantly higher achievement in mathematics on nationwide assessments when compared to their peers in comparable career/technical fields. This outcome is true for PLTW students in mathematics, reading and science in comparison to students across all career/technical fields. ${ }^{14}$ Further, PLTW students were significantly more likely to complete four years of mathematics including Algebra I, Geometry, Algebra II, and one higher level mathematics course. ${ }^{15}$

One critique of Project Lead the Way focuses on its learning objectives independent of other coursework a high school student may take. A National Science Foundation study conducted by researchers at the University of Wisconsin, Madison expressed concerns for students who relied on PLTW coursework exclusively to provide them with sufficient math skills to complete high school requirements. The study found that PLTW curriculum addresses "far fewer mathematics content and standards when compared to academic curricula" and therefore should not be considered an appropriate substitute for core mathematics classes. It should be noted that PLTW's role in Career and Technology Education has, in the past, prohibited these courses to stand in for core subject areas. ${ }^{16}$ A small study after-graduation of PLTW students who enrolled in college found that about $40 \%$ were studying engineering and technology as compared to only $4.3 \%$ of their non-PLTW peers. ${ }^{17}$ The scope of this study featured only 171 $P L T W$ graduates and as a result should be considered preliminary in its findings.

\section{Models Aside, What Changes Learning and Student Performance?}

Educational researcher Richard Elmore argues that no single model is likely to serve all students well. Indeed, in his book, School Reform from the Inside Out, Elmore notes that there are three essentials to improving learning and performance in students regardless of the particular model adopted by a given school or district. ${ }^{18}$ As he puts it, "the problems of the system are the problems of the smallest unit" 19 , that is, the interactions between a

\footnotetext{
${ }^{13}$ Ibid. p. 5

${ }^{14}$ Bottoms, G. \& Anthony, K. (2005) Project Lead the Way: A pre-engineering curriculum that works. A new design for the high school career/technical studies. Atlanta, GA: Southern Regional Education Board.

${ }^{15}$ Bottoms, G. and Uhn, J. (2007) Project Lead the Way works: A new type of career and technocal program. Atlanta, GA: Southern Regional Education Board.

${ }^{16}$ Mitchell, Nathan, et. al. (2007) "The Structure of High School Academic and Pre-engineering Curricula: Mathematics. American Society for Engineering Education: NSF: AC2008-2566.

${ }^{17}$ Walcerz, D. (2007) Report on the third year of implementation of the TrueOutomes Assessment Ssytem for Project Lead the Way. Clifton Park, NY: Project Lead the Way.

${ }^{18}$ Elmore, Richard (2006). School Reform from the Inside Out: Policy, Practice and Performance. Harvard Education Press: Cambridge, Mass.

${ }^{19}$ Ibid. p 3.
} 
teacher and his/her student. To change student outcomes, Elmore states there must be change in (1) the knowledge and skill of teachers, (2) what is taught to the students, and (3) the relationship of the student to teachers and the content. $^{20}$ Moreover, each aspect cannot be treated independently; in fact all are interdependent and interconnected. Increasing teachers' knowledge of their subject area generally brings about new approaches in covering the content and vice versa. Likewise, more substantive relationships between teacher and student enables teachers to realize the misconceptions and eureka moments of their students, which also bring about greater understanding of the teacher's content area.

Manor New Tech High School, in many ways, represents a microcosm of many of these models of reform. It is a small school focused on the New Tech Model featuring STEM curriculum and using Project Lead the Way as a primary tool for providing students with relevant applications of key math, science and technology concepts. MNTH, with its model of teacher development and peer interactions, is also attempting to embody Elmore's three principles and to drive student achievement through the principles of high content knowledge of its teachers, rigorous teaching of content, and a new kind of teacher-student relationship.

\section{Manor New Tech High School Student Outcomes}

As stated earlier, student-based outcomes for Manor New Tech High School are limited in scope, short term, and primarily focused on student performance in state assessments and teacher perceptions of student learning or challenges related to those assessments.

\section{Figure 1: Cross Sectional Look at the Proportion of Students Passing Mathematics State Standards 2007-08 MNTH 9th Graders, TAKS Passing Rates through $11^{\text {th }}$ Grade: Mathematics*}

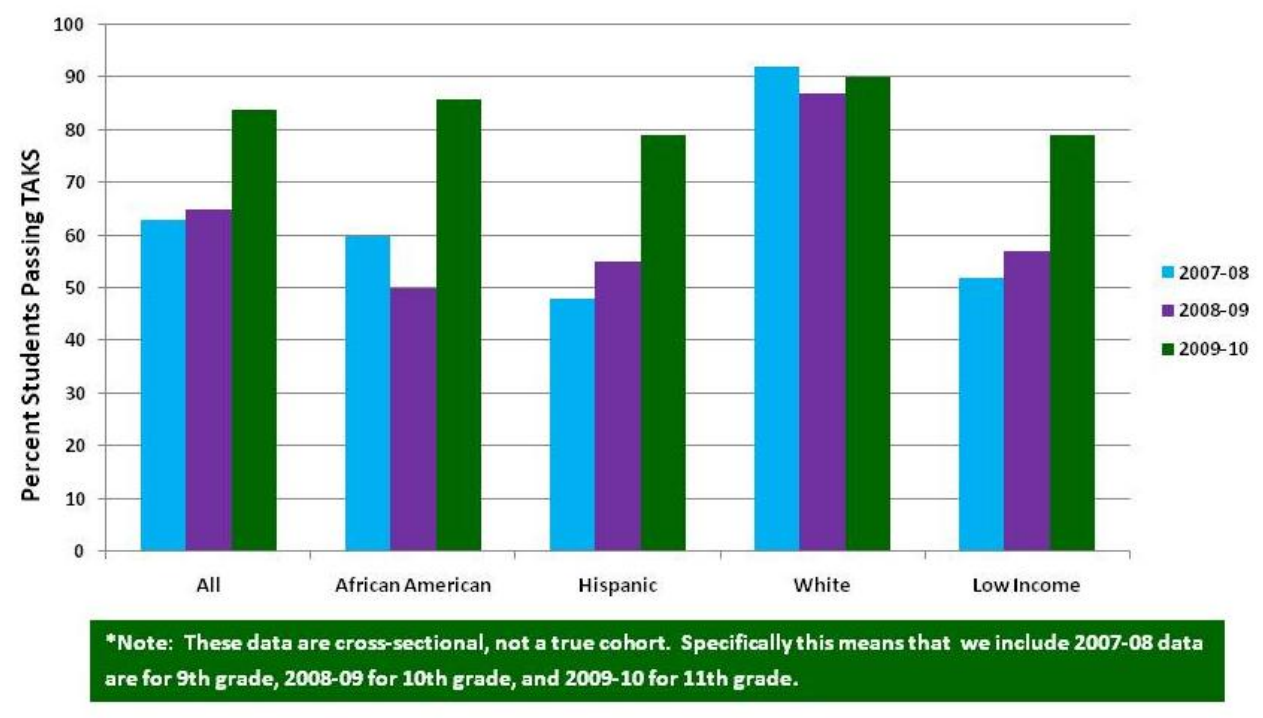

Source: Pearson Support Report, Spring 2008, 2009, and 2010

The state of Texas uses the Texas Assessment of Knowledge and Skills (TAKS) as the state standard across core subjects beginning in $3^{\text {rd }}$ grade and continuing through $11^{\text {th }}$ grade. A senior may also take these exams if she or he has not met standards at the end of the junior year. The scope of this study did not include tracking student

\footnotetext{
${ }^{20}$ From Uknow website of the Harvard Graduate School of Education: http://www.uknow.gse.harvard.edu/leadership/leadership001a.html retrieved September 1, 2009.
} 
cohorts over time. However, Figure 1 shows a cross-section by grade-level of TAKS passing rates in Mathematics beginning with the 2007-08 $9^{\text {th }}$ grade class, includes the 2008-09 $10^{\text {th }}$ grade class and ends with the 2009-10 $11^{\text {th }}$ grade class. Overall, slight to notable increases occurred in each grade for the proportion of students who met state standards in Mathematics.

Similarly, the proportion of students meeting states standards increased from $10^{\text {th }}$ grade to $11^{\text {th }}$ grade in all populations as Figure 2 shows. In the state of Texas a Science TAKS exams is not given in the $9^{\text {th }}$ grade. It is important to note that these exams are not aligned across grades in these subjects.

Figure 2: Cross Sectional Look at the Proportion of Students Passing Science State Standards

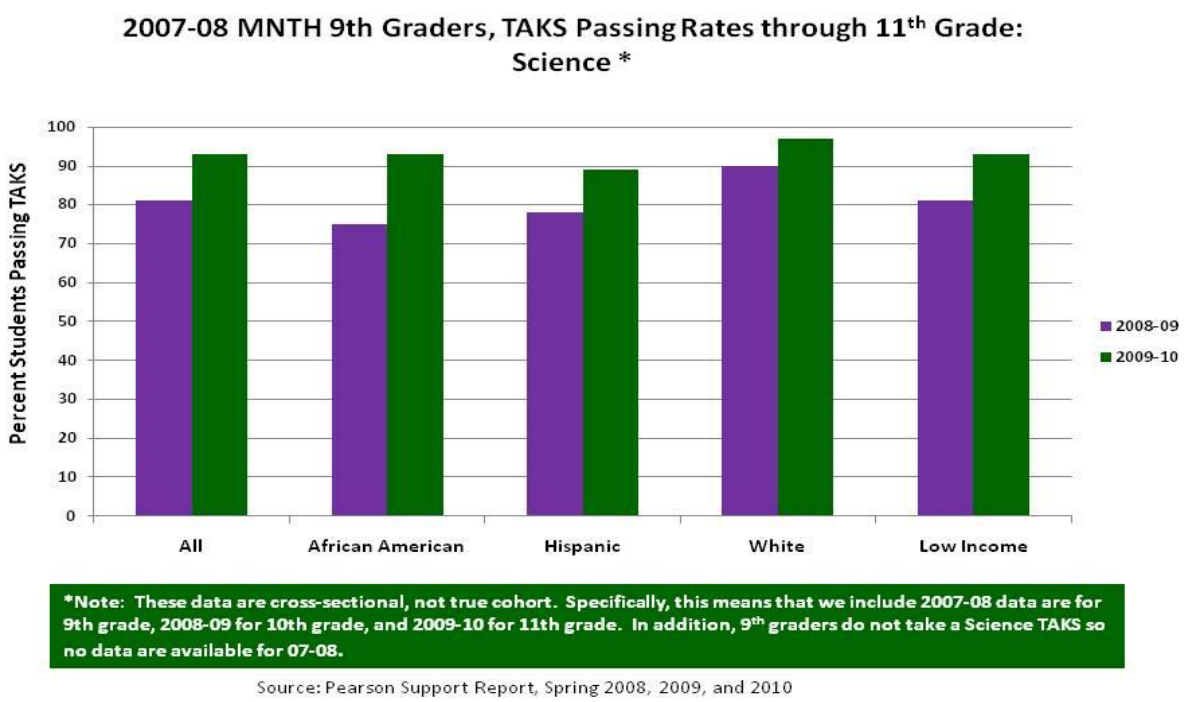

Manor New Tech High's first senior class graduated in the spring of 2010 . The principal reports a $100 \%$ graduation rate of its first class of sophomores from 2007-2008. ${ }^{21}$ The formal release of the graduation rates for the class of 2010 will not be available until November 2011. As a result, researchers are unable to confirm this passing rate.

\section{$\underline{\text { Research Findings }}$}

Initial analysis of the teacher survey responses prompted further exploration of teacher perspectives of their work and the challenges of student efficacy through teacher interviews.

In the survey question on teacher perception of student performance that asked teachers to estimate the percentage of students who are thriving, performing competently, getting by, struggling or other, teachers' responses ranged widely as shown in Table 1 below.

The broad range of responses prompted us to select for interview some of the teachers who answered this question outside the norm. For those teachers who responded that a large number of students struggled, their perception hinged on whether students had truly absorbed and adopted the practices needed to become agents in their own learning. Other teachers, whose response indicated that a large number of students were thriving or performing competently, indicated that, in comparison to their peers in other settings, these students were far more engaged and their performance was likely better than had they opted to stay in a traditional comprehensive setting.

\footnotetext{
${ }^{21}$ Although not all $10^{\text {th }}$ graders who began in 2007-08 at MNTH graduated from MNTH, all students who enrolled as $10^{\text {th }}$ graders at MNTH in that year graduated from a Texas high school by 2010.
} 
Table 1. Responses to Teacher Survey Question on Student Functioning as Learners

\begin{tabular}{|c|c|c|}
\hline Teacher Perceptions of Student Performance & Median \% & Range \\
\hline Thriving & $23 \%$ & $0 \%-70 \%$ \\
\hline Performing Competently & $50 \%$ & $0-65 \%$ \\
\hline Getting By & $18 \%$ & $4-30 \%$ \\
\hline Struggling & $10 \%$ & $4-70 \%$ \\
\hline Other & $10 \%$ & $4 \%-70 \%$ \\
\hline
\end{tabular}

Such responses, which occurred frequently, may less indicate actual student performance and may instead imply the teachers' pride of the teaching and student experiences at Manor New Tech High.

Teacher responses to both the survey and interviews revealed a myriad of school, teacher and student practices and perceptions around these practices that revealed their perception of both a positive learning environment and improved student performance.

Four overarching themes emerged from the data:

- $\quad$ Student Engagement refers to level of connection, interaction, and learning students demonstrate in classroom projects and activities.

- $\quad$ Student Agency or the level to which students take responsibility for their own learning, such as asking questions and seeking answers on their own, demonstrating critical thinking, and showing discerning use of the Internet.

- $\quad$ Support for Teachers' Work includes the range of school structures, professional development and relationship-building activities that strengthen the teachers' skills and help foster the faculty as its own professional learning community.

- $\quad$ Teacher Agency refers to the high level of autonomy in the design and implementation of classroom projects, strong classroom management, systematized processes to access students beyond the classroom setting and ability to tailor lessons and activities to meet the range of learning styles demonstrated in the classroom.

We contend that, ultimately, each of these four themes contribute toward both a culture of high expectations for teaching and learning and an environment supporting improved student outcomes, such as high graduation rates and high numbers of students successfully transitioning into post secondary settings and into promising career opportunities.

\section{Student Engagement}

Five aspects of the MNTH student experience emerged from teacher surveys responses and interviews as particularly effective in students learning of new content and skills. Three aspects, Project Based Learning, Cross Subject Project Integration, and Project Lead the Way coursework, directly affect classroom teaching and learning. Two aspects of MNTH student experience, Weekly All School Meetings and Technology Integration, affect school operations.

Project Based Learning: Teachers both in the survey and during interviews identified Project Based Learning (PBL) as critical to their success in engaging students and subsequently to improved student performance. Follow up interviews with a selection of teachers revealed certain components or characteristics of PBL that teachers found particularly effective in engaging students and developing them as learners.

1) Three of the six interviewees identified the "small group workshop" component as critical to student success particularly in teaching team work and student responsibility, and adjusting teams to meet and challenge student performances. Of those who had taught in comprehensive high schools, they found that students were more readily able to adjust to working in teams through a PBL model at MNTH than at their former school. In addition, two teachers explained that working in small group enabled more student 
choice and greater opportunity for experimentation, which in turn, heightened student engagement than working singly.

2) Two teachers specifically mentioned the "entry documents" and rubrics as essential to success in PBL. Entry documents ask for students to identify what they "know" and "need to know" at the outset of each project and are challenged to obtain the "need to know" content and skills. Each project has a rubric that provides students with the performance measures by which they will be judged on a given project, creating transparency in learning expectations and, again, fostering a sense of mutual responsibility in the teaching/learning process.

3) Two teachers commented that one of the critical aspects of PBL was students learning to ask the right questions. As a result, the focus in their classrooms included "problem-based inquiry" and the resultant compilation and organization of research around the set of questions identified by the student teams.

4) Two teachers noted that "project reflections" were important in providing the necessary post mortem by students on their own team effort. Project reflections required students to provide feedback to the teacher about the dynamics of group performance as well as about their experience in researching and completing a given project. Project reflections also enable teachers to reinforce key learning objectives expected of students within a given project.

Weekly All-school Meetings: Teachers mentioned the Weekly All-School Meetings, that is, an assembly of all students and faculty at the same day and time of each week, helped create a sense of community among the students and faculty. Typical content included announcements, including birthdays, performance milestones, team activities and school awards. It is important to note that MNTH's small school size enables assemblies each week of all students across all grades.

Cross Subject Project Integration: A third practice that teachers identified as a factor in student engagement was the practice of integrating content and skills for student learning of twp subject areas into one project. Students worked on a single project that involved engineering, social studies, English Language Arts, and science, allowing students to see the same issue from different disciplinary perspectives and with greater depth of understanding. Teachers found that students developed a more realistic outlook on the "interconnectedness of subjects" and improved their skills in formulating questions based on an inter-disciplinary approach to critical inquiry.

The interdisciplinary approach provided valuable outcome to the teachers was they could evaluate students for more than one subject area. In particular:

1) Around TAKS performance goals and TEKS objectives: For example, in September 2008, MNTH teachers set the goal that they wanted to improve math TAKS scores for their students, and so all teachers committed that every subject would incorporate mathematical concepts and skills that had proven earlier to be difficult for students to master. The good news is that the passing rate for MNTH students in mathematics greatly improved in the 2008-2009 school year.

2) Providing multiple grades for a single comprehensive student project. For example, the science teacher scored students on mastery of science content, while the English Language Arts teacher would give a grade for writing.

Mandatory Project Lead the Way Courses: MNTH required all students to take two Project Lead the Way courses, and two teachers discussed the effectiveness of PBL within the curriculum of Project Lead the Way, a national engineering curriculum designed to and build skills in engineering and raise awareness of engineering careers prior to college. The teachers found two aspects particularly influential on student learning:

1) All students at MNTH are required to take Introduction to Engineering Design and Principles of Engineering. The intent of this requirement is to help students gain a better grasp on mathematics concepts through applied approaches, and to help foster team-based problem solving skills.

2) PLTW requires business partnership through councils and classroom speaking engagements, thus providing a clear connection to the local high tech industry. For students in these classes, direct connection to local business offers them work-based learning opportunities that improve career awareness in high tech fields, offers examples of how professionals shaped their own paths through education, and grounds projects in cutting edge applications. 
Technology Integration: Of course, one of the signature characteristics of the New Tech Model is the expectation of a 1:1 ratio of student to networked computers, however access to technology does not imply effective use ${ }^{22}$. Teachers observed that taking advantage of new media, while sometimes challenging to the veterans, was critical to maintaining student engagement and adjusting to variations in learning style. Specifically, teachers found that students responded to:

1) Visual learning strategies such as video, YouTube, and Internet Research.

2) On-line learning in terms of the use of Wikis, project management tools, access to rubrics, entry documents, and so on allowing for students to become active and critical consumers of knowledge

3) Extended access to teachers and peers through text messaging, Twitter, and email.

\section{Student Agency}

In the front entrance of Manor New Tech hangs a large poster ascribing the Manor New Tech High Student Pledge. Below the words are the signatures of those students in the inaugural 2007-2008 class. This poster embodies a key mission of Manor New Tech High: students take responsibility for their learning. Teacher responses in both the survey and interviews provided evidence that treating students as agents in their own learning brought about higher expectations for themselves and student contributions towards a school-wide culture of learning. The teachers who discussed this attribute of MNTH described examples of this culture of learning as embodied by the interactions between teacher and student and between student and student.

These teachers' comments correspond to classic definitions of cultures of learning that define knowledge as "situated in the every day practices and contextual experiences" of the students. ${ }^{23}$ The teachers pointed out that changing students' culture for learning was quite challenging because these same students had experienced their previous education career as passive recipients of knowledge rather than as "empowered learners." One interviewee acknowledged that in a given $9^{\text {th }}$ grade class a teacher could find no student to enter MNTH with this sense of agency in his or her own learning. Yet, by the end of the school year as much as $30 \%$ of that same $9^{\text {th }}$ grade class had integrated this responsibility into their every day efforts in school. practices.

MNTH teachers attributed the rise of student agency to several aspects of MNTH school and classroom

1) The transparency in expectations for learning fosters greater agency because students know from the outset what they should do and what qualifies as high quality performance on their projects work.

2) Peer learning through the small group efforts encourages students to collaborate and remediate with each other. It also provides its own kind of "policing" of student responsibility. There are opportunities throughout the duration of a given project to call out a student who fails to perform allotted tasks by her own team members. In some instances the team will ask such students to leave the team. Teachers then work with the ousted student and determine whether to reassign the student to another team or have her continue on her own.

3) Teachers observed that students who did actively become agents in their learning were more likely to acquire important professional skills and integrate them into their academic behavior, such as time management, team work, critical thinking, and presentation skills.

4) MNTH provides students the opportunity to participate in decisions pertaining to school and classroom activities and projects. As a result, teachers find students more invested in these activities and often are more motivated to perform well.

Teaching in [this] way is more powerful, relevant, and rewarding than in a traditional school setting. ... This change has been very rejuvenating for me. I believe in what I am doing more than ever

\footnotetext{
${ }^{23}$ Brown, John Seely and Allan Collins. (1989) "Situated Cognition and the Culture of Learning." Education Researcher 18: 32-
} 42. 


\section{Support for Teachers' Work}

Not surprisingly, one of the most common themes from both the survey and the teacher interviews identified as unique at MNTH was the intensity and range of support provided for teachers to do their work. These supports generally fall into three categories: school structures, leadership and administrative support, and extensive year-round professional development focused on skill acquisition and relationship-building.

School structures: MNTH operating practices allow for teachers to meet regularly for common planning periods as well as formal and informal workshops in professional development. Examples of these structures include:

1) Monday late start: Faculty identified this time as critical to faculty communication and cohesion because it offered two hours each week for faculty to identify and solve problems they encountered as they worked towards the goals of teaching PBL across all subject areas, the one-to-one student to networked computer ratio, development of rubrics and student use of rubrics, and student behavior vis-à-vis the student pledge. This time was also used for important professional development (more on that later), and enabled teachers to talk about their students' performance across subject areas.

2) Small School Environment: Although few teachers overtly mentioned the small school environment with respect to teacher effectiveness, many noted aspects of smaller learning communities that were beneficial to both teachers and students. Examples of aspects benefiting both teachers and students include: smaller class sizes, Tuesday All-School Assemblies, effective all-faculty meetings, and the flat hierarchy of administrators, teachers and students.

3) Ubiquitous Technology: Several teachers noted that, although at times they felt intimidated by the amount of technology available, it was a valuable asset in PBL, classroom management, and maintaining teacher/student transparency. Further, the integration of technology into all aspects of learning and teaching enabled teachers to tailor assignments for specific learning styles.

School Leadership: All teachers interviewed expressed appreciation for the leadership at Manor New Tech High. Specifically, they identified several characteristics they believed contributed positively to their work.

1) Support for innovation: Three of the six interviewed teachers felt that they were encouraged to be creative in planning their classroom activities and projects. The principal encouraged wide latitude in creativity as long as the work was connected to state learning standards ${ }^{24}$ and appropriate for adolescent and teenage students.

2) Participating in school mission and goal setting: Three of the six teachers interviewed noted that the flat hierarchy -- as indicated by their open access to the principal and dean and participation in key decisions-contributed to their sense of commitment to MNTH and their students.

3) Actively seeking school-industry partnerships: Two of the six teachers referred to industry partnerships and connections as important in the career awareness and professional development of their students. One specifically referenced the principal's active pursuit of local business partners as supportive in the teachers' aspirations for student career awareness.

Teacher Professional Development: MNTH conducts extensive, year-round professional development for teachers in addition to required attendance at summer training and conferences. A typical MNTH teacher experienced between 150 - 174 hours of professional development over a 12-month period. Table 2 show the amount and kinds of professional development offered to teachers at MNTH. Overall MNTH professional development addressed skills and knowledge in teaching and assessing specific subject areas, use of school planning and instructional strategies such as PBL, and building strong professional relationships among the faculty.

\footnotetext{
${ }^{24}$ The Texas Essential Knowledge and Skills, known as TEKS
} 
Table 2. Types and Duration of MNTH Teacher Professional Development

\begin{tabular}{|l|l|l|c|c|}
\hline \multicolumn{1}{|c|}{ Description } & \multicolumn{1}{|c|}{ Frequency } & \multicolumn{1}{c|}{ Duration } & $\begin{array}{c}\text { Total } \\
\text { Hours }\end{array}$ & Source \\
\hline Critical Friends \& Cluster meetings & Each Monday & 2 hours & 72 & Teacher Advancement Program \\
\hline District Staff Development & 4 days a year & 6 hours & 24 & District \\
\hline Coaching by New Tech Coach & Once a week & 30 minutes & 18 & New Tech Model \\
\hline All Schools Conference & Once a summer & 3 days (or more) & 24 & $\begin{array}{c}\text { All Schools Conference + subject } \\
\text { specific conference such as CAST }\end{array}$ \\
\hline New teacher training & Once a week & 1 hour & 36 & District \\
\hline TOTAL Hours per Year & & 174 & \\
\hline
\end{tabular}

More specifically, MNTH teacher professional development included:

Developing Teaching Skills through:

1) Weekly Professional Development: Often taking place during Monday late morning start, the Teacher Advancement Program (TAP) meetings included both Cluster Meetings and Critical Friends. Interviewed teachers who were new to PBL also found that Master Teachers were essential to their success and sense of confidence. TAP Master Teachers are full time in their professional support of classroom faculty. Three teachers also stated that weekly access to the New Tech Coach helped them to strategize and trouble shoot instructional issues and classroom management.

2) Year Round Professional Development: As required, MNTH teachers participate in summer professional development and are also partially compensated for it. Both surveyed and interviewed teachers ranked the All Schools Conference for New Technology High Schools as of greatest value. Teachers who ranked it first remarked that at this conference, teachers from around the country shared PBL lessons without having to spend the first half of any workshop convincing their audience of the value of PBL. Teachers found great value in the detail around classroom activities, planning processes, grading structures that worked in mathematics, in English Language Arts, in Social Studies and in Science.

Building Professional Relationships through:

1) On-Demand Professional Development: The structure of the Teacher Advancement Program requires the availability of mentor and master teachers to address problems that arise weekly and--at times-- daily.

2) Paired-Teacher Model: All MNTH teachers have a co-teacher. In the survey, a majority of teachers cited "my co-teacher" as the person whom they most "valued and turned to for professional support". Follow-up interviews revealed that teachers constantly referred to the co-teacher as integral to their planning and implementation of classroom projects and an essential "sounding board."

\section{Teacher Agency}

At MNTH, faculty described a strong sense of community and camaraderie that they believed arose in part from the strong support they received in their work. When asked about what they valued most in the survey about working at MNTH, 5 of 19 teachers specifically talked about the culture, while an additional 5 stated their "peers" and fellow teachers or the "collaboration" among peers. This culture of high expectations in learning and in teaching characterized the interactions at MNTH in faculty-faculty interactions, faculty-student interactions, and less consistently - in student-student interactions. The concept of culture is defined by Richard Elmore as the instructional core and is more difficult to quantify, but considered a critical factor in school success. School improvement, according to Elmore, occurs through improving the instructional core or "increasing teacher's knowledge of content and how to connect that content to specific students, by increasing the pre-requisite knowledge that students bring to their interactions with teachers and by deepening their own knowledge of themselves as learners." ${ }^{25}$ 
More specifically, teachers in both the surveys and interviews used language such as "empowered," "more effective," "successful in my work" as very important and contributing toward a sense of being able to reach students. Still additional factors were also mentioned.

If my kids graduate and they are not college and career ready, that's on me. - from interviews

1) Group Dynamic in Goal Setting: Teachers play an active role in setting MNTH's annual goals and in clarifying and extending its mission. In addition, teachers felt a greater sense of responsibility toward meeting those goals for their students. Elmore argues such a sense of agency leads toward a school-wide "internal accountability", that is, all faculty work at the same level of expectation for student outcomes as well as their own role or responsibility in ensuring students meet these expectations. Again, as Richard Elmore notes: "The ability of a school to make improvements has to do with the beliefs, norms, expectations, and practices that people in the organization share, not with the kind of information they receive about their performance., 26

2) Strong Communication: Most teachers interviewed noted that MNTH varied significantly from other high schools in their experience because of the openness and frequency of communication among faculty and staff. Teachers felt their input was valued by both peers and leadership contributing to sense of mutual commitment and mission about Manor New Tech High. Further, some teachers described the transparency in communication with students that resulted in increased levels of trust students felt. One teacher noted that, while she did not think that teachers were more caring at MNTH, students perceived that they cared more about them and knew more about them than their counterparts in traditional high school settings. In the surveys, another teacher noted that while collaboration among faculty was strong, that communication still needed improvement among staff and between faculty and students.

3) Modeling work ethic: As both an asset and a challenge, teachers in both interviews and surveys pointed out the exceptional work load that they face at MNTH even with smaller class sizes. Veteran teachers new to the MNTH environment observed that they felt like brand-new teachers in their facing the requirements of PBL and the use of technology and hours spent beyond instructional time planning and revising projects for their classes.

4) Dedicated, creative faculty: Teachers repeatedly referred to a strong sense of community and, more importantly, of a community of mentors. At any given time, because of the frequency of faculty meetings, teachers knew who they could seek out to answer specific questions about instruction (content or strategy). Survey responses showed that over half the faculty valued most their peers and the innovative thinking they demonstrated.

Teachers overwhelmingly emphasized the positive environment they experienced and they perceived their students experienced at MNTH; however, not surprisingly, the school was not without its challenges.

\section{$\underline{\text { Teacher Challenges }}$}

While MNTH had challenges that, according to teachers, were both typical of any school and also unique to the New Tech Model. Chief among the latter was the immense workload felt by teachers in preparing content with the PBL instructional approach. All interviewed teachers noted the workload, and two teachers specifically commented that teachers "looked for signs of burn out" among their fellow teachers. A few instances, MNTH teachers encouraged peers to take time off in order to decrease work-related stress.

A second challenge identified by teachers that also is unique to newly-launched, innovative schools was a perception in the district that MNTH took the best students and therefore deprived Manor High School of its higher performing students. Teachers did not claim that there was a direct impact on teacher effectiveness. However, they

${ }^{26}$ Ibid. p. 206 
were concerned about the perceptions of their peers across other district campuses as well as parent morale for those high school students who attended Manor High School. Although there were demographic differences across the two campuses, too many variables such as school size, type of faculty, implementation of PBL or any of the other practices mentioned above, could result in disparities in student performance across the two campuses. During the 2008-2009 school year this perception remains a challenge.

A third issue identified by teachers as a challenge for them and a benefit for students was the trimester system. The trimester system allows students to take more courses during their four years of high school. However, it requires that teachers completely cover course curricula within less time than in a traditional semester system. Teachers felt added pressure for MNTH to find a balance between PBL and direct instruction.

Perhaps the greatest challenge was that MNTH primarily served teenagers living in poverty or near-poverty and many entered MNTH lacking key foundational knowledge in core subjects such as math and science. Also, as discussed above, students were unaccustomed to an ethic in which they were "agents in their own learning." With students coming from impoverished backgrounds, often lacking foundational skills and knowledge, and not yet agents of their own learning, only half of the teachers responding that they felt students "performed competently" in the MNTH environment with others finding a large proportion of students (median 28\%) were either just "getting by" or "struggling."

A further complication identified in two interviewed teachers was that for some students, increased input into classroom projects and strategies led to a sense of entitlement. This entitlement occasionally resulted in classroom behavior of challenging or disagreeing with classroom and school rules, creating new challenges to classroom management.

Given both positive outcomes and yet remaining and new challenges, we describe in the following section three practices from these findings that show promise in application to traditional high school settings. We choose the application to traditional high school settings because the majority of school districts across our region--and the nation--lack the resources to scrap the traditional comprehensive high school model altogether and instead are looking for systemic adaptations that can lead to improved teacher effectiveness and higher levels of student achievement.

\section{Recommendations: Selected Practices for Application in Comprehensive High School Settings}

High school reform and redesign researchers repeatedly have found that near term positive outcomes are more likely when launching a brand new school like Manor New Tech High rather than the redesign of existing under-performing large high schools. ${ }^{27}$ A study by the American Institutes for Research and SRI International found that positive outcomes are more likely in new schools, in part, because older schools focus first on structural changes rather than addressing teacher instruction. ${ }^{28}$ Furthermore, as noted by high school redesign researcher and consultant, Bob Pearlman (2007):

Large high school conversion requires design, implementation and effective change management to bring about successful small schools in addition to district leadership and support and effective small school leadership. ${ }^{29}$

In selecting three promising practices from the many possible options identified in our findings, we applied the following criteria as a filter:

1. Did a majority of teachers (both surveyed and interviewed) identify this practice as connected to teacher or student success?

\footnotetext{
27 National Evaluation of High School Transformation (2006). American Institutes for Research and SRI International. "Evaluation of Bill \& Melinda Gates Foundation's High School Grants Initiative: 2001-2005 Final Report. p. 79

${ }^{28}$ Ibid.

29 Pearlman, Bob. (2007) Best Practices. North Eugene High School. Retrieved July 23, 2009 from http://www.bobpearlman.org/bestpractices/NorthEugeneHighSchoo.htm
} 
2. Was there evidence (either as described through survey answers or interviews or through a review of literature) that suggests the practice leads to teacher agency or improved student outcomes?

3. Are there examples where similar practices have been undertaken successfully at traditional comprehensive high schools?

4. Can the planning and implementation of these practices occur in a timely manner without exhausting available district or school resources?

Finally, these selected practices draw upon Richard Elmore's three principles to improving performance discussed in the literature review. Thus, the final criterium is that the practice affects the kinds of classroom interactions between teacher and student.

As a result, the following recommendations focus on (a) increasing student engagement through PBL and (b) strengthening support for teachers' work. We hypothesize that increasing both student engagement and support for teachers' work will increase student agency and teacher effectiveness leading to improved overall student achievement.

We recommend that comprehensive high schools:

1) Adopt Project Based Learning strategies in core courses beginning in $9^{\text {th }}$ grade

2) Provide extensive professional development to teachers in PBL throughout the calendar year and offer professional development to administrators in developing school structures to support PBL

3) Restructure the school schedule to allow for weekly common planning periods and focused teacher interactions, ideally both late start days for all-faculty professional work and common planning periods for teacher teams and pairs to develop instruction together.

1. Adopt Project Based Learning Strategies in core courses beginning in $9^{\text {th }}$ grade. In 1996, Linda Darling Hammond published a seminal report based on longitudinal research that found quality teaching was paramount to student success. In part, her study claimed that such teachers were not identified by any specific set of credentials but instead by their ability to adapt their teaching to student learning styles and to create classroom environments that were interactive and engaging. ${ }^{30}$ It is important to note that this report predates the proliferation of PBL as an established instructional model, however the principles of student engagement and agency in learning that guide PBL are the same foundational characteristics described by Darling-Hammond.

Further, PBL need not be situated solely in STEM-related classes. Indeed, as one of our non-STEM teachers interviewed noted of her classroom:

Students must become independent learners - teachers help to guide, remove barriers, and do not hold their hands. [The approach] helps students to build their ability to "question" and to pinpoint the important questions.

2. Provide extensive professional development to teachers in PBL throughout the calendar year and offer professional development to administrators in developing school structures to support PBL.

One underlying theme that teachers at MNTH either implied or explicitly stated was the level of support they had and needed in creating PBL-based classes. One veteran teacher interviewed stated that when he came to MNTH, he felt like a first year teacher all over again. For many teachers Project Based Learning requires not only a shift in how they teach but also requires rebuilding what they understand about their teaching. For core subjects in the state of Texas, the learning objectives within specific grades may remain the same, but to create projects that apply these concepts in real-world settings takes a high level of knowledge in content, in pedagogy, and an awareness of industry-uses for these concepts. Four of the six interviewed teachers noted that having full time master teachers and instructional coaches readily available on any given day to help troubleshoot or work through project planning contributed greatly to their sense of efficacy and ability in taking on this new way of teaching.

\footnotetext{
${ }^{30}$ Darling-Hammond, Linda. (1996) What Matters Most: Teaching for America's Future - Report of the National Commission on Teaching and America's Future.
} 
Pearlman (2007) points out successful high school reform requires school leadership that is well-versed in both change management and in implementing strategies that support changes to organizational culture. The flattened hierarchy, the faculty meetings that focused on problem solving and involved two-way communication, having a suite of professional development that met teachers' needs and interests as they developed all requires school administrators to behave outside the model of more school principalships. Therefore, we recommend that if a school faculty or part faculty undertake PBL instruction, the school leaders also receive professional development in skills to listen to teacher voices and create supports and incentives for teachers' success in PBL instruction.

3. Restructure the school master schedule to allow for weekly common planning periods and focused teacher interactions.

The challenge to the type of extensive professional development described above for traditional comprehensive high schools is having school structures that directly support teacher work and professional development in PBL. Specifically, MNTH used Monday late start as the foundation consistently and continually throughout the year. The time allotted allowed teachers to share concepts and lesson plans with their peers for feedback, and ongoing support occurred through cluster meetings.

Launching a small school (200-400 students) with less district oversight than its peers allows a new way of teaching along with development of its school leaders and changes to its schedule to be more easily implemented than at a traditional high school. Only some traditional comprehensive high schools have faculty meetings to share problem solving, common planning periods, and campus instructional coaches or master teachers. ((Note that a faculty of 22 at MNTH had two full-time master teachers in addition to weekly access to New Tech coaches.) These traditional campuses that are implementing such practices are at the frontier of changing teacher work that Elmore (2003) cites as the environment creating substantive changes in student learning and achievement.

\section{Follow Up Research Questions for teacher professional development and school structure modifications}

1. How much does MNTH faculty's close attention and emphasis on PBL affect student engagement and agency as compared to their peers at a traditional comprehensive high school?

2. How does Project-Based Learning address challenges to "sufficient instructional time," a factor often cited when explaining low student performance?

3. What is the relationship between student engagement and agency and student achievement?

4. How does the leadership in a traditional comprehensive high school provide ongoing professional development and common planning time for teachers throughout the school year?

5. What central administration supports enable these approaches?

6. What is the relationship between this ongoing professional development in PBL and teacher agency?

7. How does MNTH student performance fare relative to comparable T-STEM academies launched in the same year? What differences, if any, exist between T-STEM models that are stand alone versus "schools within schools?"

\section{CLOSING REMARKS}

This research of teacher experiences at Manor New Tech High finds that both teacher agency in lesson development and delivery and student agency in their own learning are crucial in creating a new kind of high school experience for students. While the student performance data is still young, many teachers noted that MNTH is in the spotlight as a model that can make a difference in student achievement - in particular, for those students who have traditionally struggled in education. This report offers suggestions of practices emerging as contenders in contributing to teacher and student agency - to a sense of personal responsibility and commitment both in teaching and in learning.

At the end of the day, the seismic shifts in education underway at the state and federal levels register only if the interactions in the classrooms engage, challenge and empower students to learn. At Manor New Tech High, the challenges are substantial, the progress measurable, and - from the perspective of the teachers - the rewards ample. 
To paraphrase the words of the great poet, Khalil Gibran, "The Teacher is wise ... who gives not of his wisdom... but leads you to the threshold of your own mind."

\section{ACKNOWLEDGEMENT} Division

Research findings from National Science Foundation, Grant Award EEC-0835961, Engineering Education

\section{AUTHOR INFORMATION}

Dr. Hannah Gourgey has worked for over a decade in workforce development and education in Austin. At E3 Alliance, Dr. Gourgey facilitates regional efforts to increase college and career readiness among high school graduates and cultivates partnerships with schools, community and business organizations to help drive systems change in education throughout Central Texas. Prior to joining E3 Alliance, Dr. Gourgey worked at Skillpoint Alliance, first as Managing Director of the Community Technology Training Centers and then as Deputy Director and acting Executive Director for the organization. During her tenure at Skillpoint, Dr. Gourgey spearheaded the effort that launched the High School Graduate Data Center - a regional longitudinal research project dedicated to tracking Central Texas high school graduates after they leave high school. In addition to her work in the community, Dr. Gourgey has taught at the University of Louisville and the University of North Carolina Chapel Hill and The University of Texas at Austin. Dr. Gourgey holds degrees from Northwestern University, the University of North Carolina Chapel Hill, and the University of Texas at Austin.

Dr. Bahram Asiabanpour is an Associate Professor of Manufacturing Engineering and a Certified Manufacturing Engineer (CMfgE). He has served at Texas State University-San Marcos since 2003. He has two years work experience in a car design company in tool design and CAD/CAM positions. He has published several journal and conference papers and two book chapters in the areas of CAD data extraction, machine path generation, rapid tooling, selective inhibition of sintering (SIS) rapid prototyping process, CAD/CAM, product and process development, process optimization, and education. He has designed and taught four new senior-level courses including capstone senior design, tool design, manufacturing systems design, and computer aided design and manufacturing as well as other undergraduate and graduate courses. He has also enlisted the support of local industries and government agencies in his teaching and research activities. He is the director of the Rapid Product and Process Development (RPD) research center at Texas State University- San Marcos. He was the CoPI for an NSF REU center grant. For this grant in summer 2008 and 2009 his department hosted 20 undergraduate students to conduct research entitled "Micro/Nano Assembly Workcell Via Micro Visual Sensing and Haptic Feedback". Additionally, Dr. Asiabanpour collaborated with E3 Alliance and University of Texas at Austin as CoPI for an NSF project entitled "Central Texas Engineering Education Collaborative" to improve the supply chain for engineers. Dr. Asiabanpour is member of the Society of Manufacturing Engineers (SME) and the Institute of Industrial Engineers (IIE).

Dr. Carol Fenimore Safari has broad experience in school and district administration as well as deep knowledge of curriculum and instruction, particularly in teaching K-12 mathematics. Throughout her career, Dr. Fenimore Safari has been identified by her fervent commitment to provide all students - regardless of ethnicity, family income or language proficiency - with excellent teachers and schools, particularly in learning mathematics, science and literacy. Dr. Fenimore Safari's first teaching experience was in mathematics and science while a Peace Corps volunteer in the West Indies, and she has taught in Houston, Texas and conducted field research in Boston, Massachusetts and Syracuse, New York. She has been a district administrator in Georgetown, Texas and Fresno, California and a high school administrator in Austin, Texas. Dr. Fenimore Safari is currently the Director of Student Success Initiatives at E3 Alliance, which is the P-16 Council for Central Texas. Dr. Fenimore Safari holds a Bachelor of Science in Applied Mathematics from Brown University, a Master of Arts in Teaching Mathematics from Colgate University, and a Doctorate in Education from Harvard University. 


\section{APPENDIX A: On-Line Survey Administered to MNTH Faculty, April 2009}

Have you had a career before teaching?

Name up to three careers that you have worked in before becoming a teacher.

Has (have) your previous career(s) contributed toward your preparation or ability to teach?

If so, please describe how your previous career(s) has (have) contributed to your preparation or ability to teach.

How many years have you taught, including this year?

How many years have you been certified to teach? (Please count from your first certification onward and include this year.)

Please list up to six TEXAS certification(s) in teaching, supervision or counseling that you currently hold. For each certification, name the SUBJECT AREA (or enter "supervision" or "counseling") and GRADE LEVEL. Please mark any provisional or emergency certifications with an asterisk.

Do you hold any out-of-state teaching, supervision, or counseling certifications?

If you currently hold OUT-OF-STATE educator certification(s), please list each. Include the STATE, the SUBJECT AREA (or enter "supervision" or "counseling") and the GRADE LEVEL. Please do not include provisional or emergency certifications.

When did you start teaching at MNTH?

What is the main reason that you accepted a position here at MNTH?

What SUBJECT AREAS do you teach this year at MNTH?

Please name or list up to eight topics of PROFESSIONAL DEVELOPMENT that you have received in the last year. Include professional development during the summer of 2008, during late start days, and that occurred off-campus.

Which of the professional development topics named above do you consider the most essential to teaching MNTH students? If none of the professional development you named were essential, please enter "None" for your answer.

Explain how this particular professional development topic contributes to teaching MNTH students. (If you answered "None", please skip this question.)

In your opinion, what percentage of MNTH students fit the following descriptions of LEARNERS?

If you entered a percentage for "Other" in the question above, please describe:

Name or list up to eight INSTRUCTIONAL PRACTICES that you use at MNTH to engage your students. Based on your experience, please list these practices in order of effectiveness, listing the most effective practice first, the second most effective practice second, and so on.

Who is your most supportive colleague at MNTH?

In what ways has he or she been supportive?

What, in your opinion, makes this school a NEW TECH high school?

What do you value the most about working at MNTH?

Explain WHY the aspect you named above is to valuable to you.

This ends the on-line survey. If there is anything else on which you would like to describe or elaborate, please do so below.

If you would like to receive a copy of the written report based, in part, on this survey, please enter your e-mail address below: 